\title{
Using Transformative Learning Theory to Impact Patient Care
}

Reitha Cabaniss

Bevill State Community College, Jasper, Alabama, United States

*Corresponding author: Reitha Cabaniss Bevill State Community College, 1411 Indiana Ave, Jasper, Alabama- 35501, Tel : 205-387-0511 ext. 5740; Fax: 205-295-2602 United States, E-mail : racabaniss@bscc.edu

Received date: November 06, 2014, Accepted date: December 15, 2014, Publication date: December 18, 2014

Copyright: @ 2014 Cabaniss R. This is an open-access article distributed under the terms of the Creative Commons Attribution License, which permits unrestricted use, distribution, and reproduction in any medium, provided the original author and source are credited.

\begin{abstract}
This article explores the use of Mezirow's Transformative Theory in nursing education. The author offers compelling evidence to broaden the use of this theory by nurse educators in designing curricula while incorporating national standards of practice and safety guidelines.

Addressing the disorienting dilemmas facing nursing, letting go of out dated frames of reference can positively impact patient care.
\end{abstract}

\section{Introduction}

The history of nursing demonstrates an incredible resolve to ensure quality and safety for patients. Evidence of quality and safety competencies is present in nursing publications, standards of practice and accreditation guidelines [1]. Education is regarded as the conduit to needed improve quality in the health care system by providing the necessary link to creating the transformation [2]. Nursing students must be prepared with a different set of knowledge, skills and attitudes if quality and safety of health care is to improve [3]. This article explores Mezirow's Transformative Theory and reviews utilization of the theory by nurses. The author offers compelling evidence to broaden the use Transformative Theory and ultimately transform health care.

\section{Background}

The 1999 Institute of Medicine's (IOM) landmark report, To Err is Human: Building a Safer Health System, concluded that thousands of preventable deaths were occurring in U.S. hospitals due to mistakes in direct patient care [4]. A follow-up IOM report was released in 2001, Crossing the Quality Chasm: A New Health Care System for the 21st Century, calling for major changes in healthcare organizations and for educational institutions to align conditions toward providing care that is safe, effective, patient-centered and efficient [5]. These findings transmitted shockwaves through both the healthcare industry and higher education [6]. Health Professions Education: A Bridge to Quality acknowledged the education of health professionals as a bridge to quality care and concluded that health professionals' education had not kept current with actual healthcare needs [7]. Specific areas for improvement included concepts such as evidence-based practice, technology advances, diversity changes and new leadership requirements. Clinical education was considered to also have fallen behind lacking adequate responses to evolving health care practice requirements [8]. It is apparent that graduating nursing students are not prepared to transition into nursing practice environments with critical quality and safety competencies [9].

In higher education programs, curriculum is one of the key elements in preparing students for occupations in a global society. Course curricula are commonly taught based on the view of faculty. A majority of faculty often lack opportunity to participate in review and assessment of the suitable dimension of courses offered at their respective institutions [10]. There are broader political and practical contexts to consider which frame the requirement for competent practice. The establishment of clear and unmistakable connections between expectations upon entering professional practice, appropriate utilization of technology and the inclusion modern pedagogical strategies are essential to promote a true knowledge shift [11]. Knowledge production and current approaches to education have become more externally positioned and supervised beyond the university setting. In many instances, specialized education has shifted from professional knowledge to application $[12,13]$.

Nursing curricula is undergoing scrutiny in many U.S. states. Goals of curriculum redesign address the current nursing shortage, increase the educational preparation of practicing nurses, and foster smooth transition from the educational institution to the practice setting [14]. Educators and clinical leaders are examining traditional clinical learning assignments to determine effectiveness in meeting the challenges facing the health care system [15]. In many instances the apprenticeship model is utilized in the clinical setting with disease and illness oriented curricula taught in the classroom. Faculty often teach in a manner in which they were taught during nursing school, focusing on covering content [16]. Scholarly teaching for nursing education is being challenged by existing workplace standards [12]. Reconsideration of traditional assumptions about formal education and curriculum is required to prepare proficient graduates with appropriate skills for the twenty-first century [11].

The National Council of State Boards of Nursing (NCSBN) [17] reported the number of new graduates successfully passing the National Council of Licensure Examination (NCLEX-RN) in 2010 at 123,158 . These newly licensed nurses represent the number of nurses eligible to transition into the nursing workforce. NCSBN also reported the extent of registered nurses in the United States holding active license in 2010 at 3,853,870, which depicts the huge influence on delivery of patient care [17].

In the position statement, Nursing: A Call to Reform, the National League for Nursing called for innovation and stated that previous attempts to reform nursing education have resulted in a reshuffling of course content instead of significant changes [18]. Nursing 
Page 2 of 4

educational leaders are obliged to confront individual frames of reference held by nurse educators to promote transformation and the inclusion of appropriate aspects of quality and safety curricula.

In higher education programs, curriculum is one of the key elements in preparing students for occupations in a global society. Course curricula are commonly taught based on the view of faculty. A majority of faculty often lack opportunity to participate in review and assessment of the suitable dimension of courses offered at their respective institutions [10]. There are broader political and practical contexts to consider, which frame the requirements for competent practice. The establishment of clear and unmistakable connections between expectations upon entering professional practice, appropriate utilization of technology and the inclusion modern pedagogical strategies are essential to promote a true knowledge shifts [11]. Knowledge production and current approaches to education have become more externally positioned and supervised beyond the university setting. In many instances, specialized education has shifted from professional knowledge to application of professional knowledge $[12,13]$.

\section{Transformative Learning Theory}

Transformative Learning addresses the shift of consciousness experienced when confronted with a disorienting dilemma [19]. The focus of transformative theory implies that presumptions and ways of being come under examination and challenge deeply held viewpoints. Adults encounter disorienting dilemmas and grapple with decisions, ideas, values and beliefs, which to this point have fit their way of thinking or habit of behavior. This process creates emotional stress, but can lead to transformation of former perspectives [20]. The goal of transformative learning is to understand personal actions and views that drive decisions by exploring the values and knowledge on which the conclusions are based [21].

Transformative Learning begins with a disorienting dilemma that triggers passionate responses demanding critical reflection of personal assumptions, attitudes and beliefs. Vulnerability occurs when existing perspectives are questioned. This process is uncomfortable and often takes time to resolve, as new ideas and frames of reference are confronted [20]. Critical reflection is required to decisively explore and understand the basis of personal perceptions. The theory provides strategies to foster transparent, thoughtful decisions and lead to sustained perspective transformation (Mezirow, 2000). Mezirow describes seven levels of reflection as Reflectivity, Affective Reflectivity, Discriminate Reflectivity, Judgmental Reflectivity, Conceptual Reflectivity, Psychic Reflectivity, and Theoretical Reflectivity [22,23].

Perspective transformation is described as the process of becoming critically aware of how and why personal assumptions have come to constrain the way humans perceive, understand, and feel about the world; changing these structures of habitual expectations to make possible a more inclusive, discriminating, and integrative perspective; and finally making choices or otherwise action upon these new understandings [20]. When an individual's habitual expectations or beliefs are changed, this results in perspective transformation [24].

According to Mezirow and Associates [19], the process of perspective transformation consists of 10 phases. The ten steps of the process do not have to be followed in linear progression. Learners may stop along the process of perspective transformation for extended or brief periods of time (p. xii). Mezirow noted that a standstill was more likely when important relationships are threatened. The ten phases are:

- A disorienting dilemma.

- Self-examination with feelings of fear, anger or shame.

- A critical assessment of assumption.

- Recognition that one's discontent and the process of transformation are shared.

- Exploration of options for new roles, relationships and actions.

- Planning a course of action.

- Acquiring knowledge and skills for implementing one's plans.

- Provisional trying of new roles.

- Building competence and self-confidence in new roles and relationships.

- A reintegration into one's life on the basis of conditions dictated by one's new perspective (p. 22).

\section{Disorienting Dilemmas in Nursing}

Disorienting dilemmas currently facing the nursing progression are multi-faceted. Nursing curricula are overloaded with content and curricula is often superficially taught leading to deficient understanding which threatens adequate provision of patient care $[25,26]$. A 2008 report from the Agency for Healthcare Research and Quality reveals that preventable medical injuries are increasing annually by $1 \%$ in spite of a national focus on patient safety and quality improvement. This calls into question adequate integration of patient safety and quality improvement content in the curricula of health care professionals [27].

In the United States, the landmark Carnegie study conducted by Benner, Sutphen, Leonard, and Day documented the insufficient training of nurses, including poor quality of classroom instruction, limited assimilation between classroom and clinical experience, lack of adequate pre-requisites and curricular requirements and disappointment with the teaching -instruction preparation of current nursing faculty [28]. Orsolini-Hain and Malone describe factors contributing to an imminent decline in clinical nursing expertise. The authors cite an increased proportion of practicing novice nurses (less than one year clinical experience) to experienced nurses and the increased rate of veteran nurse and nurse educator's retirement as a critical threat to sustaining delivery of safe nursing care [29].

\section{Review of Research}

A review of research utilizing Mezirow's transformative learning theory in nursing education was conducted. Several database searches were conducted accessing: Proquest, ERIC, PubMed, CINAHL. Criteria for selecting studies were based on the use of transformational learning as the primary theoretical framework and findings which support the purpose of the proposed research. Each study had a sample and methodology segment and offered findings supporting the utilization of transformative learning theory. A bulk of studies utilize transformational learning theory to modify student perceptions [30], evaluate students' journal writings using Mezirow's stages of reflection [31] and scrutinize development of professionalism in RN-BSN students [32]. One study explored innovative pedagogies used in nursing education [33]. 
Page 3 of 4

\begin{tabular}{|l|l|l|l|}
\hline Modify Student Perceptions & Student Journal Writings & $\begin{array}{l}\text { Development of Professionalism } \\
\text { in RN-BSN program }\end{array}$ & Innovative Pedagogies in Nursing Education \\
\hline $\begin{array}{l}\text { Ruth-Sahd, Beck \& McCall, } \\
{[29]}\end{array}$ & $\begin{array}{l}\text { Horn \& Freed, } \\
{[30]}\end{array}$ & Morris \& Faulk, [32] & $\begin{array}{l}\text { Brown, Kirkpatrick, Greer, Matthias, \& Swanson } \\
\text { [33] }\end{array}$ \\
\hline & Jensen \& Joy [31] & & \\
\hline
\end{tabular}

Table 1: Research Summary: Transformative Learning Theory as Primary Theoretical Framework. Total - 5 studies

\section{Purposes and Settings of Research}

The studies are grouped in how they enlighten some characteristic of transformational learning. Nursing students used critical reflection to apply transformational learning in the classroom and clinical settings to confront assumptions of pre-licensure students in a summer externship program [29], develop professionalism as a BSN prepared nurse [32], describe clinical problem solving and quantify the level of reflection through student journaling [30,31]. One study explored the pedagogical style and non-traditional educational strategies used by nurse educators [33].

Most studies were situated in formal higher education nursing classrooms [30-33]. The remaining studies looked at a summer clinical externship program and innovative classroom strategies utilized by international nurse faculty $[29,33]$.

\section{Research Methods}

The majority of research methods make use of a qualitative research design but employ different approaches. Ruth-Sahd, Beck and McCall [33] used individual discussions, focus group discussions and reflective surveys to collect data from pre-licensure nursing students participating in a summer clinical program. Qualitative techniques were used to analyze the associate degree nursing student weekly journals and guided question responses. Levels of student reflections were different between the students working in pairs as opposed to those working independently [30]. A group of junior baccalaureate nursing students wrote three journal entries while taking a health assessment course. Investigators reviewed the journal entries for progression of student reflections using Mezirow's seven levels of reflection [31]. Morris and Faulk examined responses to open-ended questions from recent $\mathrm{RN}$-to-BSN graduates requesting the respondents to identify learning activities which create re-socialization and critical reflection of BSN roles and values specified by the American Association of Colleges of Nursing (AACN) [32].

The only quantitative research design used an electronic survey. The survey was distributed to 10, 467 Sigma Theta Tau International members to explore the most up-to-date pedagogies utilized among nurse educators. The three part survey utilized drop down lists, multiple check boxes options and blank lines for open responses [33].

\section{Impact of Transformative Learning Research}

The research findings focus on student reflections within a variety of settings. The pre-licensure summer clinical externship program was found to positively impact externs' perceptions, values and beliefs about entering nursing practice [29]. Students working in pairs demonstrated stronger associations with classroom theory and practice than students working individual [30]. Mezirow's levels of reflection were found to be useful for evaluation of student reflection. These results suggest that the seven levels of reflection can be used to challenge traditional beliefs in beginning nursing students [31].

Morris and Faulk [32] concluded that changes in professional behavior can occur by planning learning activities in nursing curricula. Professional behavior changes were observed as superior connection with the health care team, improved patient advocacy, and increased confidence in the patient-family teacher role.

The investigators found that a majority of respondents see the teacher role as facilitator and information provider. The conventional teacher-centered approach remains the most prevalent teaching style. Additionally, the findings uncover the continued utilization of traditional teaching methods among nurse educators which hinders innovation and transformation in nursing education [33].

The majority of nursing literature focuses on transforming student perspectives, using critical reflection as a means to socialize RN-BSN nursing students, or to challenge assumptions of innovative clinical experiences. Literature describing transformation of faculty perspectives about the educator role and curriculum is limited. The implications for utilization of research based findings into curricula and student clinical experiences are needed.

\section{Conclusion}

Literature describing transformational learning as a means to challenge nurse educators' frames of reference to impart curriculum change was non-existent. Nursing education leaders must confront individual frames of references and long-held traditions [34-37] by nurse educators to promote transformation in curricula used to prepare nurses for transition in to practice [16]. Transformative Learning theory may be the missing connection to endorse sustained change within the nursing profession. This theory affords faculty and practicing nurses a sound vehicle to critically examine assumptions and beliefs and respond with thoughtful decisions and long lasting actions. The process of critical reflection and dialogue with trusted colleagues is essential to achieving legitimate perspective transformation leading to sustained improvement.

Nursing faculty must examine their frame of reference of teaching to incorporate strategies to best prepare nursing graduates for a complex health care system. The nursing profession faces lingering nursing shortages, increasingly complex health care systems, new nurse graduates unprepared to meet emerging health care demands, continued increased occurrences of safety errors, overloaded contentladen curricula, and a nursing workforce with a majority educated in associate degree nursing programs [16],Transforming education which impacts nursing should begin with nurse educators. New clinical recommendations must be incorporated into contemporary health care practices. The attitudes and beliefs of nurses can be shaped 
Page 4 of 4

and transformed to apply progressive measures which improve patient care.

\section{References}

1. Cronenwett L, Sherwood G, Barnsteiner J, Disch J, Johnson J, et al. (2007) Quality and Safety Education for Nurses. Nurs Outlook 55: 122-131.

2. Sherwood G (2011) Integrating quality and safety science in nursing education and practice. Journal of Research in Nursing, 16, 226-240.

3. Bargagliotti LA, Lancaster J (2007) Quality and safety education in nursing: more than new wine in old skins. Nurs Outlook 55: 156-158.

4. Keeping patients safe: Institute of Medicine looks at transforming nurses' work environment. Qual Lett Healthc Lead (2004) 16: 9-11, 1.

5. Institute of Medicine (IOM) (2001) Crossing the Quality Chasm: A New Health Care System for the 21st Century.

6. White D (2006) The Identification of best practices in teaching quality competencies for preparing future healthcare leaders. The Journal of Health Administration Education, Winter, 68-93.

7. Institute of Medicine (IOM) (2003) Health Professional Education: a Bridge to Quality

8. Finkelman A, Kenner C (2007) Teaching IOM-implications of the Institute of Medicine reports for nursing education. Silver Springs: American Nursing Association.

9. Sullivan DT1 (2010) Connecting nursing education and practice: a focus on shared goals for quality and safety. Creat Nurs 16: 37-43.

10. Schuerholz-Lehr S, Caws C, Van Gyn G, Preece A (2007) Internationalizing the higher education curriculum: an emerging model for transforming faculty perspectives. Canadian Journal of Higher Education, 17, 67-94.

11. Hipkins R, Reid A, Bull A (2010) Some reflections on the philosophical and pedagogical challenges of transforming education. The Curriculum Journal, 21, 109-118.

12. Lee A, Dustin R (2011) Practice, learning and change: towards a retheorisation of professional education, Teaching in Higher Education, 16, 483-494.

13. Kreber C (2006) Developing the scholarship of teaching through transformative learning. Journal of Scholarship of Teaching and Learning, 6, 88-109.

14. Lewis L (2010) Uniting States, sharing strategies: Oregon takes the lead in addressing the nursing shortage. Am J Nurs 110: 51-54.

15. Durham CF, Sherwood GD (2008) Education to bridge the quality gap: a case study approach. Urol Nurs 28: 431-438, 453.

16. Tanner C (2010) Transforming prelicensure nursing education: preparing the new nurse to meet emerging health care needs. Nurse Education

17. Tamm ER, Schmetterer L, Grehn F (2013) Status and perspectives of neuroprotective therapies in glaucoma: the European Glaucoma Society White Paper. Cell Tissue Res 353: 347-354.
18. NCSBN (National Council of State Boards of Nursing) (2010) Nurse licensure and NCLEX examination statistics.

19. National League for Nursing (NLN) (2003) Nursing education: a call to reform.

20. Mezirow JA, Associates (2000) Learning as transformation: Critical perspectives on a theory in progress. San Francisco: Jossey-Bass.

21. Chirema KD (2007) The use of reflective journals in the promotion of reflection and learning in post-registration nursing students. Nurse Educ Today 27: 192-202.

22. Matthew-Maich N, Ploeg J, Jack S, Dobbins M (2010) Transformative learning and research utilization in nursing practice: a missing link? Worldviews Evid Based Nurs 7: 25-35.

23. Mezirow J (1981) A critical theory of adult learning and education. Adult Education Quarterly, 32, 3-24.

24. Mezirow J (1996) Contemporary paradigms of learning. Adult Education Quarterly, 46 (3), 60- 61.

25. Brady D, Welborn-Brown P, Smith D, Giddens J, Harris J, et al. (2008) Staying afloat: surviving curriculum change. Nurse Educ 33: 198-201.

26. Giddens JF, Brady DP (2007) Rescuing nursing education from content saturation: the case for a concept-based curriculum. J Nurs Educ 46: 65-69.

27. Sorra J, Famolario T, Dyer N, Nelson D, Khanna K (2008) Hospital survey on patient safety culture 2008 comparative database report. Rockville, MD: Agency for Healthcare Research and Quality (AHRQ).

28. Benner P, Sutphen M, Leonard V, Day L (2009) Education nurses: A call for radical transformation. San Francisco Jossey-Bass.

29. Orsolini-Hain L, Malone RE (2007) Examining the impending gap in clinical nursing expertise. Policy Polit Nurs Pract 8: 158-169.

30. Ruth-Sahd LA, Beck J, McCall C (2010) Transformative learning during a nursing externship program: the reflections of senior nursing students. Nurs Educ Perspect 31: 78-83.

31. Van Horn R, Freed S (2008) Journaling and dialogue pairs to promote reflection in clinical nursing education. Nurs Educ Perspect 29: 220-225.

32. Jensen SK, Joy C (2005) Exploring a model to evaluate levels of reflection in baccalaureate nursing students' journals. J Nurs Educ 44: 139-142.

33. Morris AH, Faulk D (2007) Perspective transformation: enhancing the development of professionalism in RN-to-BSN students. J Nurs Educ 46: 445-451.

34. Brown ST, Kirkpatrick MK, Greer A, Matthias AD, Swanson MS (2009) The use of innovative pedagogies in nursing education: an international perspective. Nurs Educ Perspect 30: 153-158.

35. Hegge MJ, Hallman PA (2008) Changing nursing culture to welcome second-degree students: herding and corralling sacred cows. J Nurs Educ 47: 552-556.

36. Ellenbecker $\mathrm{CH}$ (2010) Preparing the nursing workforce of the future. Policy Polit Nurs Pract 11: 115-125.

37. Chenot TM, Daniel LG (2010) Frameworks for patient safety in the nursing curriculum. J Nurs Educ 49: 559-568. 